\title{
Past explosive outbursts of entrapped carbon dioxide in salt mines provide a new perspective on the hazards of carbon dioxide
}

\author{
Hedlund, Frank Huess
}

Published in:

Intelligent Systems and Decision Making for Risk Analysis and Crisis Response

Publication date:

2013

Document Version

Early version, also known as pre-print

Link back to DTU Orbit

Citation $(A P A)$ :

Hedlund, F. H. (2013). Past explosive outbursts of entrapped carbon dioxide in salt mines provide a new perspective on the hazards of carbon dioxide. In C. Huang, \& C. Kahraman (Eds.), Intelligent Systems and Decision Making for Risk Analysis and Crisis Response: Proceedings of the 4th International Conference on Risk Analysis and Crisis Response, Istanbul, Turkey, 27-29 August 2013 (pp. 763-769). CRC Press.

Communications in Cybernetics, Systems Science and Engineering - Proceedings

http://www.crcpress.com/product/isbn/9781138000193

\section{General rights}

Copyright and moral rights for the publications made accessible in the public portal are retained by the authors and/or other copyright owners and it is a condition of accessing publications that users recognise and abide by the legal requirements associated with these rights.

- Users may download and print one copy of any publication from the public portal for the purpose of private study or research.

- You may not further distribute the material or use it for any profit-making activity or commercial gain

- You may freely distribute the URL identifying the publication in the public portal 


\title{
Past explosive outbursts of entrapped carbon dioxide in salt mines provide a new perspective on the hazards of carbon dioxide.
}

\author{
Frank Huess HEDLUND \\ COWI; Parallelvej 2,DK-2800 Kongens Lyngby,Denmark..E-mail:fhhe@cowi.dk ${ }^{a}$ \\ Technical University of Denmark (DTU/IMM) DK-2800 Kongens Lyngby, Denmark. \\ E-mailfhh@imm.dtu.dk \\ ${ }^{a}$ corresponding address
}

Major parts later published in: Huang C and Kahraman C (eds) Intelligent systems and decision making for risk analysis and crisis response. pp763-769. Taylor and Francis (2013).

\begin{abstract}
This paper reports on a source of past carbon dioxide accidents which so far has only been sporadically mentioned in the literature. Violent and highly destructive outbursts of hundreds of tons of $\mathrm{CO}_{2}$ occurred regularly, if not routinely, in the now closed salt mines of the former DDR. The Menzengraben mine experienced an extreme outburst in 1953, possibly involving a several thousand tons of carbon dioxide. This source of accidents fills an important gap in the available carbon dioxide accident history and may provide a unique empirical perspective on the hazards of handling very large amounts of $\mathrm{CO}_{2}$.
\end{abstract}

\section{INTRODUCTION}

Carbon dioxide capture and storage (CCS) schemes will involve handling and transportation of $\mathrm{CO}_{2}$ on a hitherto unprecedented scale and magnitude. For instance, capturing and storing the emissions from a standard large 1,000 MW coal-fired power plant will require handling of about 30,000 tons $\mathrm{CO}_{2}$ per day. In contrast, today's largest inventories of pressurized carbon dioxide are found in storage terminals for commercial carbon dioxide, a large storage tank holds about 300-350 tons, and the combined storage capacity may be 1,000-1,500 tons (Hedlund 2012).

Most CCS projects currently under consideration involve pipeline transport to the injection facility. Transmission pipe-line risk studies have assumed that block valves will close in case of pipeline damage and limit the release amount to the inventory of a single pipeline section. To give a sense of magnitude and scale a severed 150 bar 19 " pipeline section only $8 \mathrm{~km}$ long may release 1,300 tons of carbon dioxide in about 3-4 minutes (DOE 2007).

The safety of the general population in the vicinity of a transmission pipeline is a potential concern. Gaseous carbon dioxide is often regarded as non-toxic and inert. Carbon dioxide is nowhere near meeting the criteria for being a toxic substance and is therefore not subjected to existing industrial safety legislation, for instance the European Seveso Directive. However, it is a potential concern if the handling of unprecedented large quantities, could result in carbon dioxide having major accident potential, to the effect that CCS projects become an emerging industrial risk.

\section{THEORETICAL HAZARD ANALYSIS}

A number of studies have reported the application of dispersion modeling techniques to predict hazard ranges for carbon dioxide transmission pipeline failures. The overwhelming consensus seems to be that hazard ranges are modest. For instance, worst case hazard analysis for the release of 1,300 tons of carbon dioxide in about 3-4 minutes suggests that acute life threatening concentrations may result within $70 \mathrm{~m}$ from the point of release and that no serious threat to 
human health exists beyond $200 \mathrm{~m}$. Some authors argue that these predictions exaggerate the hazard, and that CCS pipelines only constitute a negligible, if any, hazard potential (Hedlund 2012).

\section{PAST CARBON DIOXIDE ACCIDENT HISTORY}

The available accident history involving sudden releases of large quantities of $\mathrm{CO}_{2}$ is very limited. Pressurized storage vessels holding up to about 50 tons of liquid carbon dioxide have been a source of major accidents. Sudden catastrophic failure of the containment vessel has generated a blast wave and high-velocity fragments killing workers and causing extensive property damage. For instance, the sudden failure of a 15 bar $30 \mathrm{~m}^{3}$ carbon dioxide storage vessel in Hungary hurled a 2.8 tons fragment $150 \mathrm{~m}$, a one ton fragment $250 \mathrm{~m}$ and smaller fragments up to $400 \mathrm{~m}$, damaging several nearby residential building, killing nine workers and seriously injuring 15. Five of the fatalities were frozen to death. A layer of dry ice covered the nearby facilities making recue efforts impossible (Vörös and Honti 1974).

A natural disaster involving a large release of carbon dioxide took place in Lake Nyos, Cameroon, in 1986, involving perhaps up to 1.5 million tons. Apart from the extreme Lake Nyos disaster, accident cases on record comprise releases in the range of a few tons to tens of tons only, none in the range of hundreds or thousands of tons, which would occur in the event of a CCS transmission pipeline accident. Past accidents reported to date are therefore unable to provide an empirical perspective on predicted hazard distances for CCS projects.

\section{$4 \mathrm{CO}_{2}$ OUTBURSTS IN THE EVAPORITE DEPOSITS OF THE WERRA DISTRICT}

There is however a source of information on accidental releases of large amounts of pressurized liquid (dense phase) carbon dioxide which so far has only been sporadically mentioned in the literature. The occurrence of gas in salt mines and caverns has presented serious problems to facility operators. Salt mines have long experienced sudden, usually unexpected expulsions of gas and salt from a production face, commonly known as outbursts. Outbursts can release over one million cubic feet of methane and fractured salt, and are responsible for the lives of numerous miners and explosions. Equipment, production time, and even entire mines have been lost due to outbursts (Ehgartner et al 1998).

The potash salt mines of the Werra district in central Germany are unique for the presence of pockets of large amounts carbon dioxide in the underground. The carbon dioxide is of volcanic origin and it has migrated along local fault lines and rising basalt pipes and become entrapped in the geological formations. This is particularly true for the evaporite deposits if water has also been present. Because potash salts are highly soluble complex local re-dissolution processes can transform and redistribute salts, and carbon dioxide may become embedded in the structure of the re-crystallized salt minerals. The potash deposits are typically $500+\mathrm{m}$ below the surface and embedded carbon dioxide is in its dense phase because of the pressure exerted by the weight of the overburden.

The Werra potash deposits were discovered in the mid-1800s and early exploration drilling crews occasionally encountered major carbon dioxide pockets. In 1895, a borehole encountered a rich pocket at $347 \mathrm{~m}$ depth near Leimbach (Hundskopf). The borehole yielded high purity carbon dioxide at a pressure of 33 atmosphere gauge in quantities that made industrial production of carbon dioxide economically feasible. It eventually produced more than 50,000 tons $\mathrm{CO}_{2}$ from 1896 to 1950 . The production peaked in 1920 with 1,500 tons that year. In 1911, a sudden pressure surge took place that ruptured the surface valve, destroyed the production building and killed the guard on duty inside. While drilling a borehole near Unteralba, carbon dioxide was encountered at $687 \mathrm{~m}$ depth resulting in a geyser-like blowout which damaged the derrick and forced the drilling crew to retreat. The blowout lasted for 14 days and led to the formation of a 3-4 m tall pile of ice. Other boreholes have released up to $1,000 \mathrm{~m}^{3}$ per hour of carbon dioxide for extended periods. By 1958, the total quantity emitted from boreholes was estimated at 450 million $\mathrm{m}^{3}$ (Müller 1958:18). 


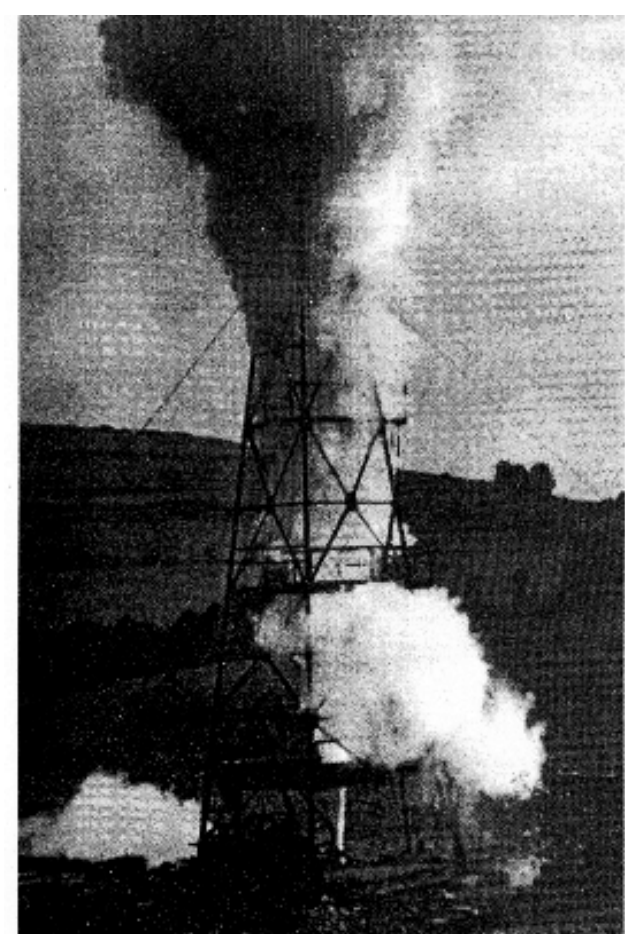

Figure 1. Pocket of $\mathrm{CO}_{2}$ encountered during exploration drilling leading to blowout (Duchrow 1997).
Pockets of carbon dioxide was also commonly encountered below ground, sometimes as loud bursts of salt, sometimes seeping out of crevices releasing flakes of dry ice into the mine tunnels. There was also a diffuse but substantial emission of carbon dioxide from the evaporite minerals, which was continuously removed by the mine ventilation system. Based on measurements of the $\mathrm{CO}_{2}$ concentration in the Menzengraben exhaust ventilation air the quantity of carbon dioxide silently emitted from this mine was estimated at $883,000 \mathrm{~m}^{3}$ per year.

The main concern was sudden violent outbursts of salt and carbon dioxide. Blasting work was known to be able to trigger major outbursts and gas-tight safety chambers were built where miners preemptively took refuge during blasting. On the 31.12.1938 two miners left a safety chamber in the Ernst Thälmann mine after blasting. Upon leaving "they suddenly heard howling and roaring winds, like the most severe storm, and the noise of overturned conveyor cars coming tumbling down the tunnels. They immediate returned to the chamber." (Müller 1958:66).

The first major release of carbon dioxide in the Menzengraben mine took place in 1926 with loud expulsions of gasses and flakes of dry ice, which continued for about eight hours. The mine crew reported a discernible temperature drop near the mine face but did not experience labored breathing even though they ventured close to the source in order to scoop up samples of dry ice in paper cups. A crew working in a nearby section of the Menzengraben mine reported powerful detonation-like blasts, each lasting for about 7-8 minutes, which reportedly sounded like machine gun fire. This particular section of the mine had abundant gas inclusions and should later produce the major outbursts of 3.6.1943, 13.10.1951 and 7.7.1953 (Müller 1958:25-27).

The Menzengraben mine was particularly plagued by outbursts, in part because large $\mathrm{CO}_{2}$ pockets were frequently encountered there, in part because the mine was relatively small; the cavity volume was about $500,000 \mathrm{~m}^{3}$ by 1953 . Because some $\mathrm{CO}_{2}$ outbursts were large and occasionally even exceeded the mine cavity volume, highly destructive gas velocities could be attained in the mine tunnel system. After a string of serious outbursts the mining authority (TBBI) in Erfurt passed an order in 1949 forbidding blasting in the Menzengraben mine when personnel were below ground. Had it not been for this order, all miners below ground would have been killed in the 1953 outburst. Less draconian measures taken to mitigate the hazard included automatically closing heavy duty drop doors to retard depressurization and attenuate destructive gas velocities in the tunnels, powerful ventilation machinery and portable selfcontained breathing apparatus for emergency evacuation carried by all miners. Preventive measures included small-bore prognosis drilling to determine the nature and $\mathrm{CO}_{2}$ content of the minerals about to be mined, which permitted a forecast of outburst probability and severity.

The sheer size of these outbursts makes them potentially interesting in a carbon dioxide hazard analysis perspective because the amounts released exceed those of the existing industrial accident history by one or two orders of magnitude. In some cases the outbursts led to uncontrolled venting of carbon dioxide to the surface exposing people above ground to the hazards of carbon dioxide. Selected cases are presented in Table 1. The mines in operation today have such large cavity volumes that outbursts are attenuated and uncontrolled surface venting is highly improbable. 
Table 1. Selected outbursts that led to uncontrolled venting of gas above ground from mine shafts.

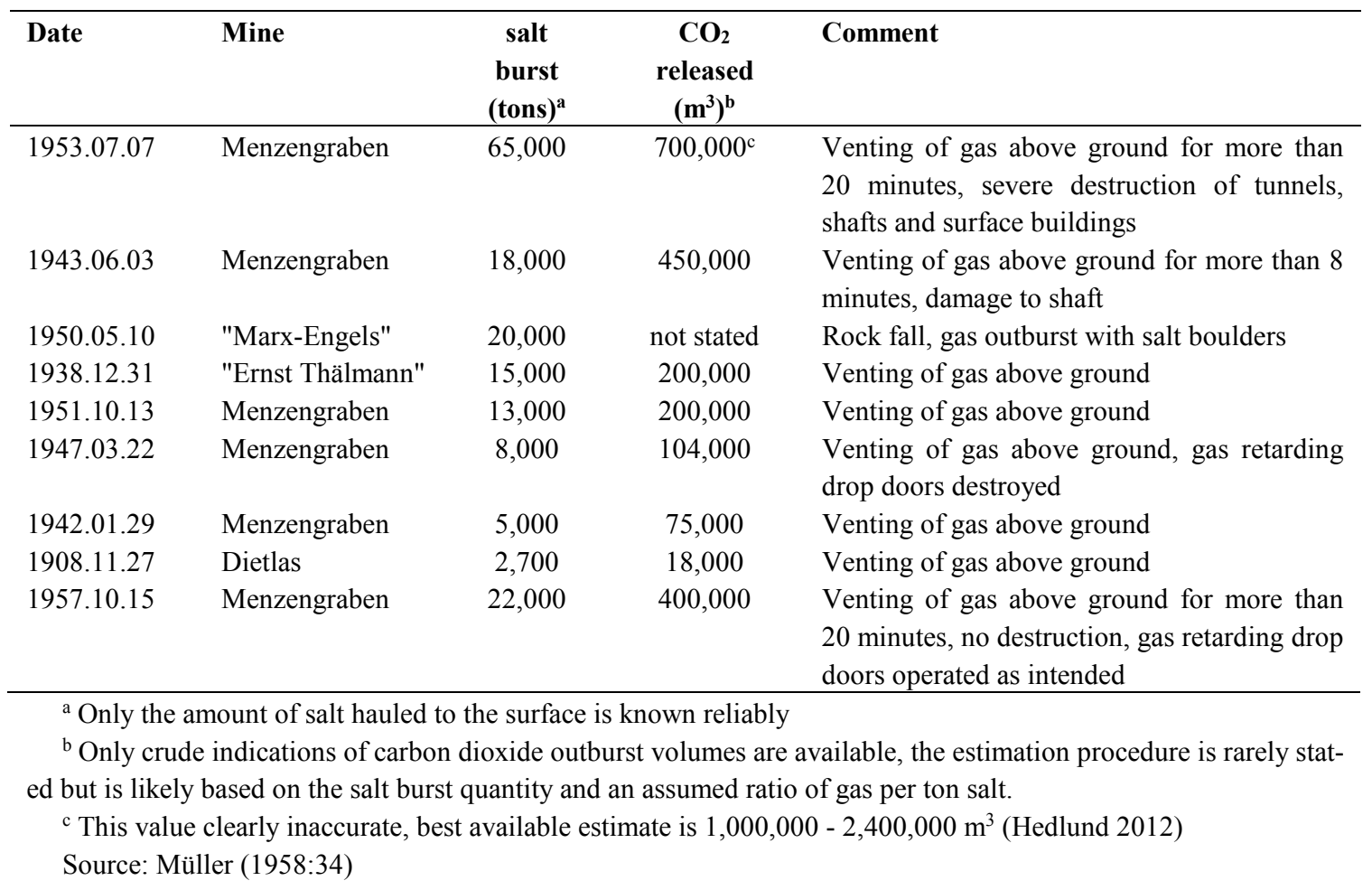

\section{THE 1953 SUPER OUTBURST}

Shortly before midnight on July 7, 1953, the Menzengraben mine experienced a "Superausbruch" (super outburst) which ravaged the mine and led to uncontrolled forceful venting of carbon dioxide at the surface for more than 20 minutes. The gas came rushing up \#2 Shaft with unprecedented force and shattered the roof before exiting "into the open air". Large amounts of splintered construction timber were scattered over "the entire area" up to $150 \mathrm{~m}$ from the \#2 Shaft House. Damage to electrical installations below ground caused a power failure which silenced the factory alarm siren. With the sky overcast the power failure left the mine and the two nearby settlements in total darkness.

The escaping gas sounded like "four to five large locomotives blowing steam at the same time accompanied by a deep rumbling undertone". The sound lasted for about 25 minutes. It was wind still and "in a relatively short time the entire valley from Stadtlengsfeld to Dietlas was completely filled with concentrated carbon dioxide" (Junghans 1953).

The outburst was triggered by blasting. Because the mining authority had issued an order forbidding blasting in the Menzengraben mine when personnel were below ground there was nobody below ground. However, a considerable number of miners from the afternoon shift, who had just left the mine, were still in the vicinity of the shaft yard (Junghans 1969:241). They had a good knowledge of the dangers of carbon dioxide and practical experience with working in potentially hazardous carbon dioxide environments below ground. The immediately fled uphill the western ridge. A contemporary newspaper reported that heroic scenes unfolded as miners at great personal risk went back and pulled unconscious fellow workers to higher ground.

The inhabitants of the two nearby settlements were initially bewildered by the wailing and then silenced siren, the electrical blackout and the noise of the escaping gas. As soon as they realized the gas danger however, they fled their homes to the safety of the heights of the eastern ridge. Junghans (1953) praised the exemplary cold-headed behavior of the individuals "though many, clad only in nightgowns, barely saved their lives". 


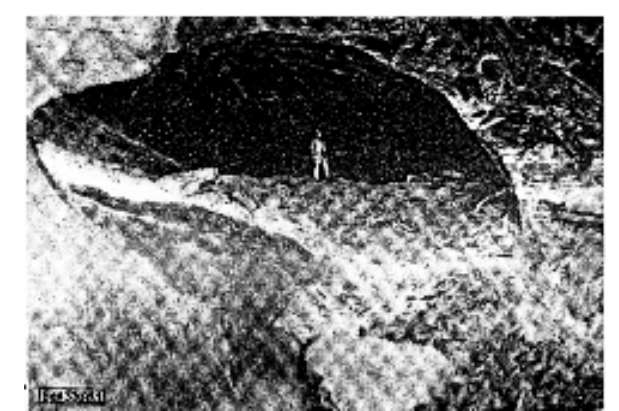

Figure 2 The opening of the cavity created in the 1953 outburst. Note person standing on pile of ejected salt for scale. The cavity, which extended $200 \mathrm{~m}$ into the salt deposits, is the largest on record. (Source: Junghans 1953)

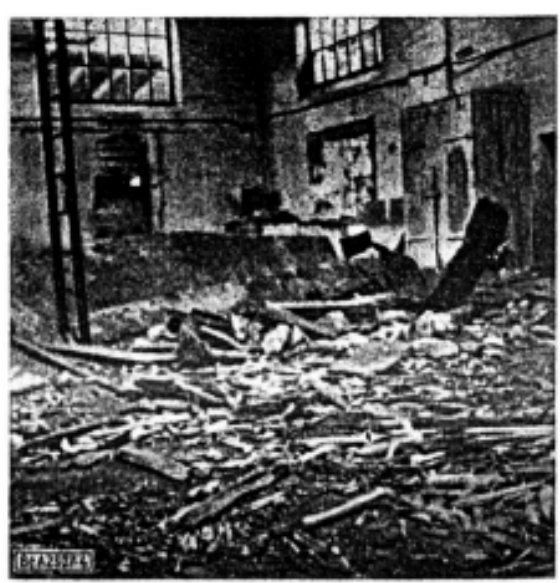

Figure 4. Interior of \#2 Shaft House. The shaft opening was partly covered by a $8-10 \mathrm{~mm}$ steel deck plate which was torn and bent upwards. Splintered construction timber and iron beams are scattered around (Source: Junghans 1953)

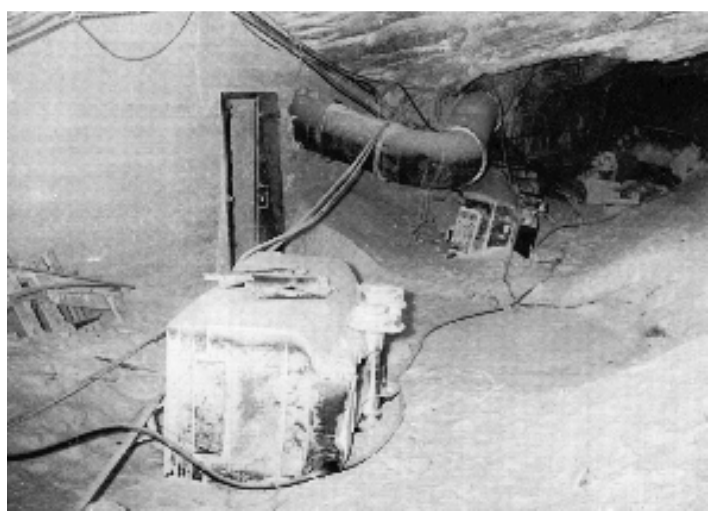

Figure 3 Destruction in tunnel. Mine rail cars hurled around by the force of the outburst, rail dislodged. Some rail cars had end walls torn off (Source: Historisches Stadtarchiv Stadtlengsfeld).

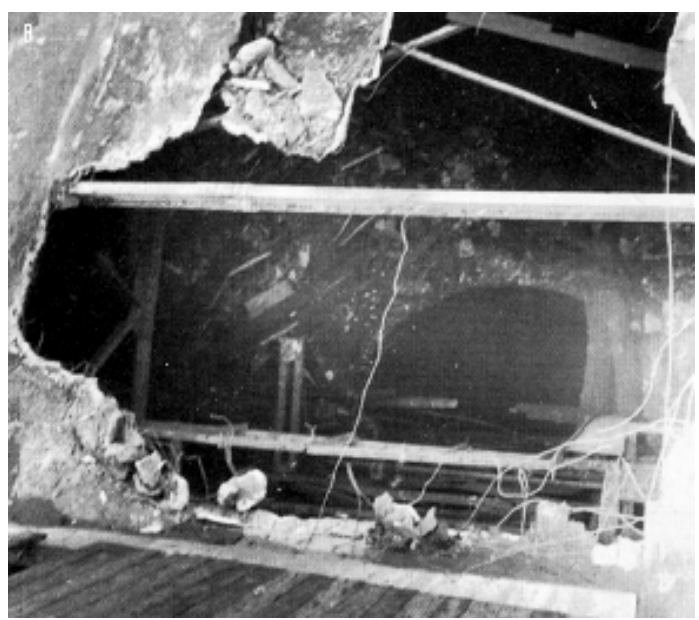

Figure 5. View through the $10 \mathrm{~m}^{2}$ opening in the iron reinforced concrete roof of \#2 Shaft House down the shaft. The gas forced its way up and shattered the roof before exiting vertically upwards (source: Historisches Stadtarchiv Stadtlengsfeld).

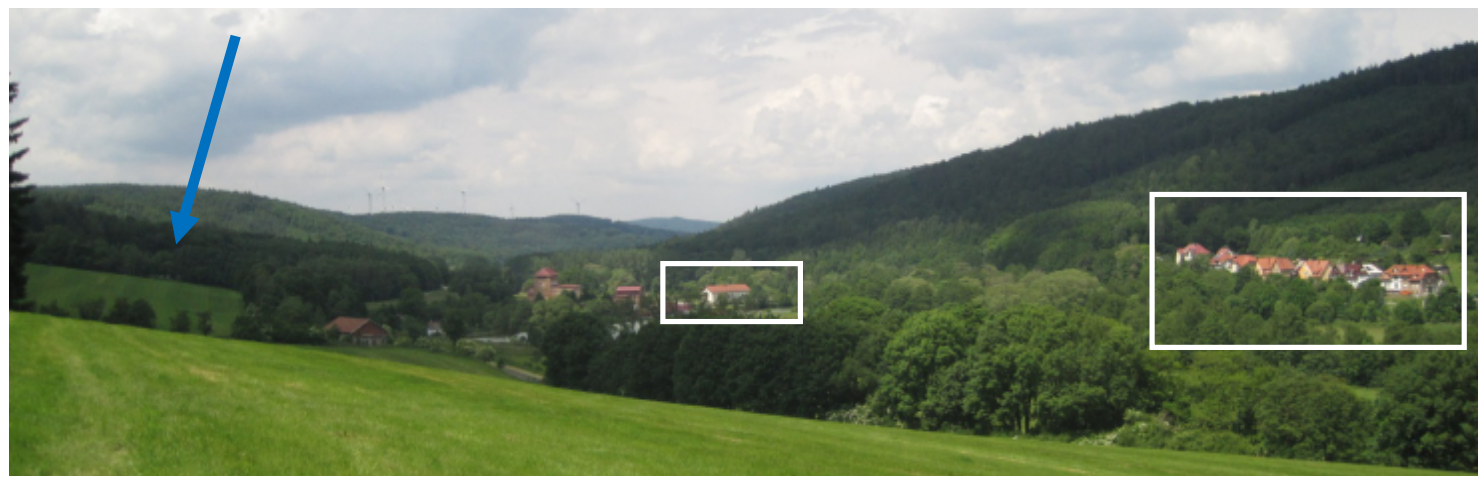

Figure 6. Location of shaft \#2 (arrow) of the now closed Menzengraben mine hidden behind tree line. The 1953 outburst flooded the "entire valley" with "concentrated carbon dioxide" and forced the inhabitants of the two miners' settlement (boxes) to flee uphill for safety. (Photo: Frank Hedlund, 2010) 
Three persons were killed. A repair shop superintendent was struck by falling debris and died from head trauma. A woman was killed due to asphyxiation in the canteen at distance 100 $\mathrm{m}$. A craftsman, died in the lowlands at distance $300 \mathrm{~m}$ due to asphyxiation. There were asphyxiation casualties (not fatalities) in a forest house $530 \mathrm{~m}$ away. Carbon dioxide concentrations of $10-30 \%$ may have occurred $450 \mathrm{~m}$ from the point of release for at least $45 \mathrm{~min}$. It is noteworthy that the two asphyxiation fatalities were non-miners (Hedlund 2012).

Hedlund (2012) examined the outburst in an industrial risk analysis perspective. Standard dispersion modeling with conservative inputs predicts that the high-momentum release from the roof of Shaft House would dilute safely and never reach ground. The predicted concentration contours cannot possibly explain the harm observed.

\section{CONCLUSION}

Accidental releases of large quantities of $\mathrm{CO}_{2}$ may provide an empirical perspective on predictive dispersion modeling. The extreme 1953 carbon dioxide outburst at Menzengraben fills a gap in the available accident history with an estimated release amount of 1,100-3,900 tons, almost two orders of magnitude larger than the largest industrial accidents currently on record. This is particularly relevant as releases of this magnitude may occur in the event of a transmission pipeline rupture associated with carbon dioxide capture and storage (CCS).

Published predicted hazard ranges for carbon dioxide transmission pipeline failures indicate that distances are modest. There seems to be general consensus that CCS activities pose limited major hazard potential. Standard dispersion modeling indicates that the 1953 Super Outburst would dilute safely and pose little hazard to its surroundings. This result is not in agreement with observed harm and witness statements than an entire valley was filled with dangerous concentrations of carbon dioxide. Additional research is required to resolve this discrepancy.

\section{ACKNOWLEDGEMENTS}

I'm grateful to Rolf Leimbach, Ortschronist, Stadtlengsfeld, for providing photos from Historisches Stadtarchiv Stadtlengsfeld.

\section{REFERENCES}

DOE, 2007. Final Risk Assessment Report for the FutureGen Project Environmental Impact Statement. Department of Energy (DoE), USA. Contract No. DE-AT26-06NT42921.

Duchrow, G. 1997 Der 100-jährige "Rhönmarsch" in die Kohlensäurefelder des Südthüringischen Kalibergbaus. Der Anschnitt. Zeitschrift für Kunst und Kultur im Bergbau 49(4):123-147.

Ehgartner, B.; Neal, J.; Hinkebein, T. 1998 Gas releases in salt. Sandia National Laboratories Report, Albuquerque, New Mexico and Livermore, California. SAND 98-1354. DOI 10.2172/656531.

Hedlund, F.H. 2012. The extreme carbon dioxide outburst at the Menzengraben potash mine 7 July 1953. Safety Science 50(3): 537-553.

Junghans, R. 1953. Der schwere $\mathrm{CO}_{2}$-Ausbruch auf der Schachtanlage Menzengraben des VEB Kaliwerk Heiligenroda am 7.7.1953, seine Ursachen und Folgen. Bergbautechnik 3(9):457-462 (part 1), 3(11):579-589 (part 2).

Junghans, R. 1969. Lehrbuch der Sicherheitstechnik. Band 1, Grubensicherheit. Deutscher Verlag der Grundstoffindustrie, Leipzig, 1969.

Müller, W. 1958. Über das Auftreten von Kohlensäure im Werra-Kaligebiet. Freiberger Forschungshefte A-101. Berlin 1958.

Vörös, M.; Honti, Gy. 1974. Explosion of a liquid $\mathrm{CO}_{2}$ storage vessel in a carbon dioxide plant. In: C.L. Buschmann (ed) Loss Prevention and Safety Promotion in the Process Industries, 1974, pp 337-346. 